\title{
О ПОКАЗАТЕЛЯХ КАЧЕСТВА ЯИЦ У КУР КРОССА Haisex Brown В ЗАВИСИМОСТИ ОТ ВРЕМЕНИ ЯЙЦЕКЛАДКИ
}

\section{А.Ш. КАВТАРАШВИЛИ}

Куриное яйцо - важный и дешевый источник питательных веществ для человека, чем обусловлен интерес к доступности этого продукта и улучшению количественного состава содержащихся в нем нутриентов. Существенный резерв в решении поставленных задач составляют морфологические характеристики яйца, так как с ними связаны некоторые показатели пищевой ценности и сохранность после снесения. Формирование яйца - длительный процесс: созревание крупных желтых иерархических быстрорастущих фолликулов в яичнике (до овуляции) занимает 7-10 сут, образование яйца в яйцеводе (от овуляции до снесения) - 22,5-26,2 ч в зависимости от возраста и продуктивности кур. На качественные показатели яйца до снесения влияет комплекс биологических факторов (порода, кросс, индивидуальные особенности, живая масса несушки, яйценоскость, время яйцекладки, возраст, условия кормления и содержания, принудительная линька, стрессы, состояние здоровья птицы), на снесенное яйцо - условия сбора, транспортировки, хранения, мойки и обработки (последствия манипуляций зависят от свойств яйца, формируемых организмом несушки). Этим определяется необходимость изучения морфологических и биохимических показателей, характеризующих качество яйща, механизмов их формирования и условий, влияющих на эти процессы. В представленной работе мы установили, что морфологические показатели качества яиц связаны со временем яйцекладки, однако в отношении разных признаков наблюдаемый эффект неодинаков. Существенных изменений в химическом составе при этом не выявили (за исключением содержание витамина $\mathbf{B}_{2}$ ). Зависимость качества яиц от времени яйцекладки изучали на курах яичного кросса Haisex Brown («Hendrix Genetics BV», Нидерланды). Исследование проводили с 210- до 450-суточного возраста несушек в типовом безоконном птичнике. Кур содержали в клеточных батареях (по 7 особей) при режиме постоянного освещения 14С (свет):10Т (темнота), свет включали в $5^{00}$, выключали в $19^{00}$. Снесенные яйца собирали в периоды $5^{00}-8^{00}\left(1-я\right.$ группа), $8^{00}$ $10^{00}$ (2-я группа), $10^{00}-12^{00}$ (3-я группа), $12^{00}-14^{00}$ (4-я группа) и $14^{00}-16^{00}$ (5-я группа). В среднем за срок наблюдения у яиц, снесенных утром (до $8^{00}$ ), была выше масса $($ р $<0,001)-$ на 2,1-2,5 г (или на 3,6-4,4 \%), а также абсолютная (на 7,2-8,7 \%) и относительная (на 1,0-1,4 \%) масса желтка (p < 0,001), следовательно, отношение массы белка к массе желтка снижалось на 4,2$8,0 \%$ (p < 0,01-0,001). У яиц, снесенных днем (с $12^{00}$ до 16 $\left.{ }^{00}\right)$ оказалось выше качество скорлупы, о чем свидетельствует ее бо́лышая масса (на 3,2-6,7 \%), толщина (на 1,8- 5,7\%) и плотность (на 0,18-0,46 \%). Индекс формы яиц изменялся криволинейно, максимальное его значение $(\mathbf{7 8 , 9} \%)$ отмечали у яиц, снесенных с $12^{00}$ до $14^{00}$, а минимальное $(77,7 \%)-$ у снесенных в конце дня (с $14^{00}$ до $\left.16^{00}\right)$. Время яйцекладки не повлияло на химический состав яиц, за исключением содержание витамина В2 в желтке: яйца, снесенные с $5^{00}$ до $8^{00}$, достоверно $(\mathrm{p}<0,05-0,001)$ превосходили снесенных в более поздние периоды дня. В партиях яиц, снесенных с $5^{00}$ до 1200, отмечали болыше боя и насечки, а в вечерних яйцах отсутствовали яйца высшей категории (> 75 г). В пределах каждого возраста показатели между группами в основном различались мало. Однако масса яйца в каждой группе с возрастом в целом повышалась. У 420- и 450-суточных несушек относительная масса белка не изменяется в зависимости от времени яйцекладки. Независимо от возраста (за исключением 210- и 450-суточного) максимальное значение индекса формы имели яйца, снесенные с $12^{00}$ до $14^{00}$ (p < 0,001-0,05). Повышенное содержание холестерина в желтке отмечали в яйцах птицы 270- и 420-суточного возраста (в целом с возрастом птицы оно повышалось), каротиноидов - у 360-суточных несушек. Содержание витамина А в желтке также имело тенденцию к повышению в зависимости от возраста кур.

Ключевые слова: Gallus gallus L., куры-несушки, время яйцекладки, масса яиц, масса желтка, масса скорлупы, толщина скорлупы, индекс формы яйца, дефекты качества, химический состав, витамин В2.

Куриное яйцо традиционно считается важным и дешевым источником питательных вешеств для человека. Продолжительность формирования крупных желтых иерархических быстрорастущих фолликулов в яичнике (до овуляции) составляет 7-10 сут, а в яйцеводе (от овуляции до снесения) в зависимости от возраста и продуктивности кур занимает в пределах 22,526,2 ч (1).

На качество куриных яиц, включающее внешние (масса и индекс 
формы яйца; чистота, толщина, масса и прочность скорлупы) и внутренние (масса белка и желтка, высота и плотность белка, цвет желтка, единицы Хау, химический состав белка и желтка) характеристики (2), влияет комплекс разнообразных факторов. Основная их часть (порода, кросс, индивидуальные особенности, живая масса, яйценоскость, время яйцекладки, возраст, условия кормления и содержания, принудительная линька, различные стрессы, состояние здоровья птицы) действует во время формирования яйца, другие факторы (условия сбора, транспортировки, хранения, мойки и обработки яиц) влияют на уже снесенное яйцо (3-7).

Во многих исследованиях установлено, что время яйцекладки влияет на качество яиц и продуктивность несушек (8-10). Так, в ряде работ показано (11-13), что самой большой была масса яиц, собранных в $6^{00}$. По сообщению R.H. Harms (14), в промышленном стаде несушек масса яиц устойчиво снижалась между $7^{45}$ и $15^{45}$, после чего повышалась. В опытах P.H. Patterson (15) наибольшая масса была характерна для яиц, снесенных рано утром, затем (с $5^{00}$ до $18^{00}$ ) она снижалась. В работе Т. Aksoy с соавт. (16) сообщалось, что яйца, снесенные в $9^{00}$, имеют самую большую массу, а после $15^{00}$ он наименьшая. Однако в опыте E. Tůmová с соавт. (17) яйца, снесенные между $10^{00}$ и $14^{00}$, были тяжелее снесенных в $6^{00}$.

Время снесения играет важную роль в формировании качества яичной скорлупы, поскольку известно, что ее масса линейно зависит от времени нахождения яйца в матке яйцевода (скорлупной железе) после овуляции и, следовательно, от толщины и прочности скорлупы (17).

В большинстве исследований отмечалось, что качество скорлупы выше у яиц, снесенных в середине дня $(11-13,18,19)$. По мнению некоторых авторов (13), более высокое качество скорлупы у «дневных» яиц связано с большей толщиной скорлупы и меньшей упругой деформаций. У таких яиц несколько выше доля скорлупы в массе яйца - 10,33 и 10,31 \% у яиц, снесенных соответственно в $14^{00}$ и $10^{00}$, по сравнению с $10,03 \%$ у яиц, снесенных в $6^{00}(18)$. Аналогичные результаты получили также Е. Tůmová c соавт. (12): в исследованиях на трех линиях кросса Dominant (Чешская Pecпублика) все параметры качества скорлупы (абсолютная и относительная масса, толщина и прочность) были достоверно выше в яйцах, снесенных в середине дня $\left(14^{00}\right)$. По сообщению R.H. Harms (14), масса скорлупы у яиц, снесенных до 745, была достоверно выше, чем в яйцах, снесенных между $7^{45}$ и $11^{45}$. Затем масса скорлупы достоверно возрастала к $12^{45}$ и оставалась высокой до конца дня, исключая лишь интервал между 1445 и $16^{45}$. Другие авторы (19), наоборот, наблюдали тенденцию к снижению массы скорлупы в течение дня, причем особенно сильно у птицы кросса ISA-Brown («Hendrix Genetics BV», Нидерланды).

При сравнении морфологических характеристик яйца у кур-несушек трех пород - Brown Leghorn, Oravka и Brahma с 20- до 64-недельного возраста при содержании на глубокой подстилке (сбор яиц в $6^{00}, 10^{00}$ и $14^{00}$ в начале, середине и конце продуктивного периода) у кур породы Brahma максимальную массу яиц отмечали в $6^{00}$, а относительная масса, прочность и толщина скорлупы были достоверно выше в $14^{00}$ (20). У коричневых леггорнов время яйцекладки не оказало существенного влияния на массу яйца, относительную массу и индекс желтка; наибольшую толщину скорлупы отмечали в $6^{00}$, а максимальные индекс белка и единицы Хау - в 1400 . У кур породы Oravka время снесения яиц не имело существенного влияния на массу яйца, относительную массу белка, желтка и скорлупы, индекс белка и желтка, единицы Хау. При этом формирование более толстой скорлупы зарегистрировано в $14^{00}(20)$. В другом исследовании (21) при сборе в $10^{00}$ 
и 1400 в первом случае масса яиц $(65,25$ против 63,94 г), абсолютная и относительная масса белка (40,91 г и 62,65 \% против 39,94 г и 62,42\%), абсолютная масса желтка (16,56 против 16,35 г) и скорлупы (7,78 против 7,64 г), индекс формы яйца (76,72 против 76,70 \%) и цвет скорлупы $(12,18$ против 12,16 балла) были выше, а относительная масса желтка (25,40 против 25,60 \%) и скорлупы (11,93 против 11,98 \%), единицы Хау (76,60 против 76,70$)$, толщина скорлупы $(0,51$ против 0,54 мм) оказались ниже.

В недавно проведенных исследованиях (22) сообщалось о значительном влиянии времени яйцекладки на содержание минеральных веществ в скорлупе. Так, максимальное содержание кальция (352 г/кг) отмечали в яйцах, снесенных в $7^{30}$, тогда как в $15^{30}$ этот показатель был на 2,84 \% ниже. Содержание фосфора и магния в скорлупе повышалось с увеличением времени снесения яиц: для $7^{30}$ эти показатели составили соответственно 1,20 и 3,56 г/кг, для $15^{30}-1,43$ и 3,88 г/кг. Некоторые авторы (23) предполагают, что более высокое содержание кальция в скорлупе утренних яиц связано с усилением депонирования кальция в медуллярной кости в темное время суток.

По данным ряда исследователей $(21,24)$, время яйцекладки влияет на интенсивность окраски скорлупы цветных яиц. Наиболее окрашенные яйца куры сносят утром, менее окрашенные - в поздний период дня. В другом сообщении (24) интенсивность окраски скорлупы снижалась с возрастом кур, а порядковый номер яйца в цикле (число снесенных подряд яиц) незначительно влиял на цвет скорлупы. Здесь, на наш взгляд, есть определенное противоречие, поскольку, как известно, первое яйцо в цикле куры откладывают рано утром, а с увеличением порядкового номера снесение отодвигается на более позднее время суток (1). Кроме того, по утверждению многих авторов (25-28), цвет яичной скорлупы положительно коррелирует с ее толщиной и прочностью, а эти показатели, как уже отмечалось $(12,19)$, наиболее высокие у яиц, собранных в полдень или в конце дня, но не утром.

Есть сведения о влиянии времени яйцекладки на уровень холестерина в яйце, при этом одни авторы отмечают повышение его содержания в утренних яйцах (17), а другие, наоборот, в дневных (29).

Таким образом, анализ научных публикаций свидетельствуют о том, что время яйцекладки существенно влияет на характеристики качества яиц. Однако по некоторым показателям данные неоднозначны и часто противоречивы, что нередко обусловлено тем, что при изучении влияния времени яйцекладки на характеристики качества яиц не всегда авторы обращают внимание на продолжительность светового или «субъективного» дня, и время первого включения света в режиме освещения, которые оказывают значительное влияние на время снесения курами яиц (1). Кроме того, следует отметить определенную генетически обусловленную специфичность влияния времени яйцекладки на некоторые показатели качества яиц. Этим обусловлена необходимость углубленного изучения морфологических и биохимических показателей, характеризующих качество яйца, механизмов их формирования и условий, влияющих на эти процессы у разных пород.

В представленной работе мы установили, что морфологические показатели качества яиц у кур Haisex Brown связаны со временем яйцекладки, однако в отношении разных признаков наблюдаемый эффект неодинаков. В среднем за весь период наблюдений у яиц, снесенных до $8^{00}$, была выше масса яйца, абсолютная и относительная масса желтка. Яйца, снесенные до полудня, имели большее число дефектов скорлупы, а у снесенных с $12^{00}$ до $16^{00}$ качество скорлупы было выше. Существенных изменений в химическом 
составе яйца в зависимости от времени снесения мы не выявили (за исключением содержание витамина В2).

Цель работы - определить показатели качества яиц у яичного кросса кур Haisex Brown в зависимости от времени яйцекладки, начиная с выхода на пиковую продуктивность.

Методика. Исследование проводили на курах промышленного стада кросcа Haisex Brown в условиях типового безоконного птичника (виварий Селекционно-генетического центра «Загорское экспериментальное племенное хозяйство» ВНИТИП, 2020 год). Из одновозрастных 210-суточных кур, содержащихся в клеточных батареях КП-112ЛМ («Пятигорсксельмаш», Россия) по 7 гол. в клетке (площадь клетки - 531 см²/особь) при постоянном режиме освещения 14С (свет):10Т (темнота) (включение света в 500, выключение в $19^{00}$ ), отобрали группу из 490 несушек. Условия кормления и содержания, не являющиеся предметом изучения в этом эксперименте, поддерживали в соответствии с общепринятыми и действующими на период проведения опытов рекомендациями (30). Яйца собирали в $5^{00}-8^{00}, 8^{00}-10^{00}, 10^{00}-12^{00}$, $12^{00}-1400,14^{00}-16^{00}$ (соответственно 1-я, 2-я, 3-я, 4-я и 5-я группы). Учетные данные регистрировали в возрастные периоды 210 сут, 270 сут, 360 сут, 420 сут и 450 сут (в каждой группе собирали по 30 яиц 3 сут подряд - на 210-212-е сут, 270-272-е сут, 360-362-е сут, 420-422-е сут, 450-452-е сут).

Определяли массу яиц (г) - индивидуальным взвешиванием на лабораторных весах с точностью до 0,1 г; выход яиц по категориям (\%) - по результатам взвешивания и осмотра яиц, снесенных курами за 3 сут подряд, согласно действующему ГОСТ («Межгосударственный стандарт ГОСТ 316542012 «Яйца куриные пищевые. Технические условия». М., 2013); индекс формы яиц (\%) - с помощью индексомера во время взвешивания; плотность яиц $\left(П, г / \mathrm{cm}^{3}\right)$ - посредством 2-кратного взвешивания (в дистиллированной воде и на воздухе) в выборке по 30 яиц от каждой группы (по 10 яиц 3 сут подряд) на одних и тех же весах (точность до 0,01 г) с расчетом по формуле: $\Pi=\mathrm{M} /\left(\mathrm{M}-\mathrm{M}_{1}\right)$, где $\mathrm{M}$ - масса яйца на воздухе (г), M1 масса яйца в воде (г); массу белка, желтка, скорлупы, массовое соотношение белка и желтка - при разделении и индивидуальном взвешивании составных частей в выборке по 30 яиц от каждой группы (по 10 яиц 3 сут подряд) (лабораторные весы, точностью измерения до 0,1 г); индекс белка (ИБ) - по соотношению высоты наружного слоя плотного белка (измерение микрометром с точностью до 0,01 мм) к среднему диаметру его растекания с расчетом по формуле: ИБ $=2 \mathrm{~h} /(\mathrm{d}+\mathrm{D}) \times 100 \%$, где $\mathrm{h}-$ высота плотного белка (мм), d и D - малый и большой диаметры вылитого белка (мм); индекс желтка (ИЖ) - по соотношению высоты вылитого на горизонтальную поверхность желтка (измерение микрометром с точностью до 0,01 мм) к среднему диаметру его растекания с расчетом по формуле: ИЖ $=2 \mathrm{~h} /\left(\mathrm{d}_{1}+\mathrm{d}_{2}\right) \times 100 \%$, где $\mathrm{h}-$ высота желтка $($ мм $), \mathrm{d}_{1}$ и $\mathrm{d} 2$ - малый и большой диаметры вылитого желтка (мм); единицы Хау по специальной таблице (32) на основании высоты белка и массы яйца; толщину скорлупы (мкм) - измерением микрометром (точность до 0,01 мм) в трех частях яйца (экваториальной, на тупом и остром концах) и расчетом среднего значения для выборки по 30 яиц от каждой группы (по 10 яиц 3 сут подряд); интенсивность окраски желтка - индивидуальной оценкой по цветовой шкале фирмы BASF.

Содержание в желтке общего холестерина, каротиноидов, витаминов А, Е и В2 (мкг/г), в белке - витамина В2 (мкг/г), в скорлупе - кальция (\%) определяли в выборке из 5 яиц (объединенная проба) от каждой 
группы 3 сут подряд в середине каждого месяца за период наблюдений.

При измерении каротиноидов (сумма) и витаминов в желтке яиц применяли единую пробоподготовку (омыление образцов 50 \% раствором гидроксида калия с последующей экстракцией диэтиловым эфиром) (32). Массовую долю витаминов А и Е определяли методом нормально-фазной высокоэффективной жидкостной хроматографии (хроматографическая система Knauer Advanced Scientific Instruments, «Knauer Engineering $\mathrm{GmbH}$ Industrieanlagen \& Со.», Германия) в соответствии с Р 4.1.1672-03 «Руководство по методам контроля качества и безопасности биологически активных добавок к пище» (М., 2003), сумму каротиноидов - колориметрически (фотометр КФК-3-01, «ЗОМЗ», Россия) с использованием бихромата калия для построения калибровочного графика с измерением OD450 (синий светофильтр). Длины волн 292 и 450 нм могут использоваться для количественного определения витамина А и каротина, так как в этой области спектры поглощения практически не перекрываются (33). Компоненты разделяли на колонке Luna 5 m Silica(2) 100 A New Column 150×4,6 mm («Phenomenex», США), элюировали смесью гексан:изопропиловый спирт (98:2), детекцию витаминов А и Е выполняли соответственно при 292 и 324 нм, в качестве стандартов использовали препараты Retinol Sigma кат. № R 7632 («SigmaAldrich», США) и (+/-)- $\alpha$-Tocopherol Fluka кат. № 95240 («Fluka», Германия).

Водорастворимый витамин В2 (рибофлавин) в желтке и белке яиц определяли флуорометрически с использованием анализатора жидкости Флюорат-02-3М (НПФНП «Люмэкс», Россия). Пробоподготовка заключалась в спиртовой экстракции (из белка $96 \%$ этанолом, из желтка 55 этанолом) с последующей фильтрацией через бумажный среднепористый фильтр («желтая полоса»). Измеряли интенсивность флуоресценции полученных растворов в ультрафиолетовых лучах, концентрацию рибофлавина рассчитывали относительно рабочего стандартного раствора витамина В2.

Для определения общего холестерина отделяли белок от желтка. Прокалывали желточную оболочку, выливали желток в стеклянную емкость и замораживали 24 ч в морозильной камере при $-20^{\circ} \mathrm{C}$. Замороженный желток помещали в лиофильную сушилку серии TFD («ilShinbiobase Co., Ltd.», Корея) на 48 ч при $-77,8{ }^{\circ} \mathrm{C}$ и давлении 5 mTorr, что позволяло высушить содержимое, удалив до 97 \% влаги, сохранив биологические активные вещества. Высушенный желток измельчали в лабораторной ступке, навеску (100 мг) смешивали с раствором Рингера в соотношении 1:100 и гомогенизировали («B. Braun Melsungen AG», Германия) в течении 1 мин при 1500 об/мин. Полученную жидкость центрифугировали при 4000 об/мин в течении 3 мин. В надосадочной жидкости измеряли концентрацию холестерина методом конечной точки на полуавтоматическом биохимическом анализаторе BS-3000P («Sinnowa Medical Science \& Technology Co., Ltd.», Китай) с проточной кюветой, используя соответствующий набор реагентов компании «ДИАКОН-ВЕТ» (Россия).

Кальций определяли по адаптированной методике (ГОСТ 26570-95 «Корма, комбикорма, комбикормовое сырье. Методы определения кальция». M., 2003) в воздушно-ацетиленовом пламени на атомно-абсорбционном спектрофотометре («VARIAN», США). Пробы готовили сухим озолением. Для приготовления стандартов использовали государственный стандартный образец (Ион кальция ГСО 7772-2000, «ЭАА Эко-аналитика», Россия).

Данные обрабатывали методами вариационной статистики в программе Microsoft Excel. В таблицах представлены средние $(M)$ и их стан- 
дартные ошибки ( $\pm \mathrm{SEM})$. Статистическую значимость различий между группами оценивали по $t$-критерию Стьюдента при $\mathrm{p}<0,05$.

Результаты. Масса - один из основных показателей качества инкубационного и пищевого яйца. С изменением массы яйца во многом изменяется и его качество (3). Результаты выполненного исследования показали (табл. 1), что время яйцекладки влияет на такой важный показатель качества яйца, как масса. Так, во все возрастные периоды и в среднем за время опыта масса яиц, снесенных с $5^{00}$ (момент включение света) до $8^{00}$ ч (1-я группа) была достоверно (p < 0,01-0,001) выше, чем позднее в течение дня. Исключение составили яйца от 450-суточных несушек: разница оказалась недостоверна, но тенденция сохранилась. В среднем за время опыта 1-я группа яиц по массе превосходила другие на 2,1-2,5 г, или на 3,6-4,4 \% (p < 0,001). Наши данные согласуются с результатами ряда авторов $(11,34-36)$, в исследованиях которых яйца, отложенные рано утром, имели бо́льшую массу, чем снесенные в остальные периоды дня. В нашем опыте яйца, собранные в $8^{00}-10^{00}, 10^{00}-12^{00}, 12^{00}-14^{00}$ и $14^{00}-16^{00}$ (2-я, 3-я, 4-я и 5-я группы) по массе различались несущественно. Однако отмечалась некоторая тенденция к снижению массы для яиц сбора с $8^{00}$ до $12^{00}$ и к повышению после $12^{00}$. Это противоречит данным Р.Н. Patterson (15), согласно которым с $5^{00}$ до $18^{00}$ масса яиц снижалась на 2-9 г. По другим данным (16), наименьшую массу также имели яйца, снесенные после $15^{00}$.

1. Масса (г) и категории яиц разного времени снесения у кур промышленного стада кросса Haisex Brown $(n=90, M \pm \mathrm{SEM}$; виварий Селекционно-генетического центра «Загорское экспериментальное племенное хозяйство» ВНИТИП, 2020 год)

\begin{tabular}{|c|c|c|c|c|c|}
\hline \multirow[b]{2}{*}{ Возраст кур, сут } & \multicolumn{5}{|c|}{ Время сбора } \\
\hline & $\begin{array}{c}5^{00}-8^{00} \\
\text { (1-я группа) }\end{array}$ & $\begin{array}{c}8^{00}-10^{00} \\
\text { (2-я группа) }\end{array}$ & $\begin{array}{c}10^{00}-12^{00} \\
\text { (3-я группа) }\end{array}$ & $\begin{array}{c}12^{00}-14^{00} \\
\text { (4-я группа) }\end{array}$ & $\begin{array}{c}14^{00}-16^{00} \\
\text { (5-я группа) }\end{array}$ \\
\hline \multicolumn{6}{|c|}{ М а с с а я й ц а, Г } \\
\hline 210 & $56,6 \pm 0,33^{a}$ & $54,2 \pm 0,37$ & $53,4 \pm 0,39$ & $54,4 \pm 0,40$ & $53,9 \pm 0,39$ \\
\hline 270 & $58,8 \pm 0,27^{a}$ & $56,1 \pm 0,35$ & $55,7 \pm 0,66$ & $56,3 \pm 0,40$ & $55,6 \pm 0,37$ \\
\hline 360 & $61,4 \pm 0,42^{a b}$ & $59,4 \pm 0,42$ & $58,8 \pm 0,39$ & $59,6 \pm 0,42$ & $58,8 \pm 0,38$ \\
\hline 420 & $61,0 \pm 0,47 a$ & $58,3 \pm 0,49$ & $57,6 \pm 0,43$ & $57,3 \pm 0,44$ & $58,4 \pm 0,41$ \\
\hline 450 & $61,4 \pm 0,47$ & $60,7 \pm 0,58$ & $60,5 \pm 0,47$ & $60,8 \pm 0,44$ & $61,3 \pm 0,42$ \\
\hline В среднем & $59,8 \pm 0,20^{\mathrm{a}}$ & $57,7 \pm 0,23$ & $57,3 \pm 0,22$ & $57,7 \pm 0,22$ & $57,6 \pm 0,21$ \\
\hline \multicolumn{6}{|c|}{ В ыход я иц по ка т } \\
\hline Высшая & 0,2 & 0,5 & 0,2 & 0 & 0 \\
\hline Отборная & 11,8 & 6,4 & 5,3 & 6,0 & 8,0 \\
\hline Первая & 76,0 & 62,7 & 63,1 & 64,4 & 60,5 \\
\hline Вторая & 10,7 & 29,1 & 29,6 & 28,9 & 30,4 \\
\hline Третья & 0 & 0,2 & 0,5 & 0 & 0,2 \\
\hline Бой и насечка & 1,3 & 1,1 & 1,3 & 0,7 & 0,9 \\
\hline
\end{tabular}

Выход яиц по категориям напрямую зависел от массы яиц. Так, в $1-$ й группе $\left(5^{00}-8^{00}\right)$ доля яиц отборной и первой категории за период 210-450 сут была выше на 3,8-6,5 и 11,6-15,5 \%, второй - соответственно ниже на 18,2-19,7 \%, чем в остальных группах. Другие группы по выходу яиц разных категории мало различались.

В 4-й и 5-й группах, где яйца были снесены в период $12^{00}-1400$ и $14^{00}-16^{00}$, число поврежденных яиц оказалось меньшее на 0,4-0,6 и 0,2$0,4 \%$. Это связано с лучшим качеством скорлупы яиц, снесенных после $12^{00}$, о чем свидетельствуют такие показатели качества скорлупы яиц, как относительная масса скорлупы, толщина скорлупы и плотность яиц (табл. 2). Как во все возрастные периоды, так и в среднем за опыт в 4-й и 5-й группах эти показатели качества скорлупы яиц были достоверно выше 
( $<<0,001-0,05)$, чем в группах яиц, снесенных до $12^{00}$. Худшими показателями качества скорлупы характеризовались 1 -я и 2-я группы $\left(5^{00}-8^{00}\right.$ и $8^{00}$ $\left.10^{00}\right)$. Полученные данные согласуются с результатами исследований (12, $18,20)$, где отмечалось, что яйца, снесенные в 1400 , имели бо́льшую относительную массу скорлупы и ее толщину в сравнении с яйцами, полученными в начале светового дня $\left(6^{00}\right)$. Авторы предположили, что масса скорлупы имеет тенденцию повышения к последнему яйцу в цикле. В проведенном позже исследовании Е. Тo̊mová с соавт. (37) указывается на зависимость массы скорлупы и, следовательно, ее прочности от продолжительности нахождения яйца в скорлупной железе яйцевода.

2. Морфологические показатели яиц разного времени снесения у кур промышленного стада кросса Haisex Brown $(n=30$, для D $n=90, M \pm S E M$; виварий Селекционно-генетического центра «Загорское экспериментальное племенное хозяйство» ВНИТИП, 2020 год)

\begin{tabular}{|c|c|c|c|c|c|}
\hline \multirow[b]{2}{*}{ Показатель } & \multicolumn{5}{|c|}{ Время сбора } \\
\hline & $\begin{array}{c}5^{00}-8^{00} \\
(1-я \text { группа })^{\mathrm{a}}\end{array}$ & $\begin{array}{c}8^{00}-10^{00} \\
(2-я \text { группа })^{\mathrm{b}}\end{array}$ & $\begin{array}{c}10^{00}-12^{00} \\
(3-я \text { группа }\end{array}$ & $\begin{array}{c}12^{00}-14^{00} \\
(4-я \text { группа })^{\mathrm{d}}\end{array}$ & $\begin{array}{c}14^{00}-16^{00} \\
\text { (5-я группа) }\end{array}$ \\
\hline \multicolumn{6}{|c|}{ Возраст 210 сут } \\
\hline \multirow{2}{*}{\multicolumn{6}{|c|}{$\begin{array}{l}\text { Масса: } \\
\quad \text { белка }\end{array}$}} \\
\hline & & & & & \\
\hline$\Gamma_{0}$ & $37,1 \pm 0,47$ & $36,5 \pm 0,50$ & $36,0 \pm 0,37$ & $36,7 \pm 0,42$ & $35,3 \pm 0,46$ \\
\hline \multicolumn{6}{|l|}{ желтка ${ }^{\mathrm{B}}$} \\
\hline$\Gamma$ & $14,6 \pm 0,16$ & $13,3 \pm 0,18$ & $13,1 \pm 0,13$ & $13,1 \pm 0,16$ & $13,0 \pm 0,16$ \\
\hline$\%$ & 25,3 & 23,9 & 23,8 & 23,4 & 23,9 \\
\hline \multicolumn{6}{|l|}{ скорлупы $\mathrm{C}$} \\
\hline$\Gamma$ & $6,1 \pm 0,07$ & $6,0 \pm 0,10$ & $6,0 \pm 0,08$ & $6,2 \pm 0,09$ & $6,2 \pm 0,11$ \\
\hline$\%$ & 10,5 & 10,4 & 10,9 & 11,1 & 11,3 \\
\hline Индекс формы яйца, \%D & $79,6 \pm 0,24$ & $78,6 \pm 0,24$ & $79,3 \pm 0,29$ & $79,4 \pm 0,22$ & $77,9 \pm 0,26$ \\
\hline 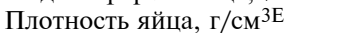 & $1,091 \pm 0,001$ & $1,089 \pm 0,001$ & $1,091 \pm 0,001$ & $1,094 \pm 0,001$ & $1,097 \pm 0,001$ \\
\hline Индекс белка, \%F & $12,5 \pm 0,36$ & $13,4 \pm 0,28$ & $13,5 \pm 0,32$ & $13,8 \pm 0,34$ & $13,2 \pm 0,36$ \\
\hline Индекс желтка, \%G & $47,9 \pm 0,42$ & $48,7 \pm 0,50$ & $48,2 \pm 0,41$ & $49,7 \pm 0,47$ & $48,4 \pm 0,56$ \\
\hline Толщина скорлупы, мкм ${ }^{\mathrm{H}}$ & $378 \pm 4,4$ & $365 \pm 4,7$ & $377 \pm 4,9$ & $386 \pm 5,2$ & $391 \pm 6,6$ \\
\hline Масса белка к массе желтка ${ }^{\mathrm{I}}$ & $2,5 \pm 0,05$ & $2,8 \pm 0,06$ & $2,7 \pm 0,04$ & $2,8 \pm 0,05$ & $2,73 \pm 0,05$ \\
\hline \multicolumn{6}{|l|}{ Интенсивность окраски } \\
\hline желтка, балл ${ }^{\mathrm{J}}$ & $2,7 \pm 0,12$ & $2,5 \pm 0,11$ & $2,8 \pm 0,15$ & $2,9 \pm 0,17$ & $2,5 \pm 0,12$ \\
\hline \multirow[t]{2}{*}{ Единицы ХауК } & $94,0 \pm 0,76$ & $95,8 \pm 0,65$ & $96,1 \pm 0,66$ & $96,1 \pm 0,63$ & $94,6 \pm 0,84$ \\
\hline & \multicolumn{4}{|c|}{ В о з раст 270 сут } & \\
\hline \multicolumn{6}{|l|}{$\begin{array}{l}\text { Macca: } \\
\text { белка }\end{array}$} \\
\hline$\Gamma$ & $36,4 \pm 0,30$ & $35,7 \pm 0,25$ & $35,7 \pm 0,31$ & $35,5 \pm 0,32$ & $34,9 \pm 0,40$ \\
\hline$\%$ & 62,2 & 63,6 & 63,5 & 63,3 & 61,6 \\
\hline \multicolumn{6}{|l|}{ желтка ${ }^{\text {B }}$} \\
\hline$\Gamma$ & $16,0 \pm 0,27$ & $14,6 \pm 0,16$ & $14,5 \pm 0,17$ & $14,5 \pm 0,16$ & $15,6 \pm 0,38$ \\
\hline$\%$ & 27,4 & 26,0 & 25,8 & 25,8 & 27,5 \\
\hline \multicolumn{6}{|l|}{ скорлупыC } \\
\hline$\Gamma$ & $6,1 \pm 0,05$ & $5,8 \pm 0,09$ & $6,0 \pm 0,16$ & $6,1 \pm 0,09$ & $\begin{array}{l}6,2 \pm 0,11 \\
10.9\end{array}$ \\
\hline$\%$ & 10,4 & 10,4 & 10,7 & 10,9 & \\
\hline Индекс формы яйца, \%D & $79,7 \pm 0,27$ & $79,6 \pm 0,24$ & $79,7 \pm 0,24$ & $80,4 \pm 0,27$ & $79,0 \pm 0,27$ \\
\hline Плотность яйца, г/см ${ }^{3 \mathrm{E}}$ & $1,088 \pm 0,0001$ & $1,087 \pm 0,0010$ & $1,090 \pm 0,0020$ & $1,093 \pm 0,0010$ & $1,093 \pm 0,0010$ \\
\hline Индекс белка, \%F & $12,5 \pm 0,34$ & $13,4 \pm 0,37$ & $13,5 \pm 0,45$ & $13,1 \pm 0,46$ & $12,4 \pm 0,36$ \\
\hline Индекс желтка, \%G & $46,2 \pm 0,43$ & $47,1 \pm 0,52$ & $45,5 \pm 0,54$ & $46,7 \pm 0,53$ & $46,3 \pm 0,47$ \\
\hline Толщина скорлупы, мкм ${ }^{H}$ & $372 \pm 4,0$ & $365 \pm 5,7$ & $383 \pm 7,3$ & $388 \pm 6,1$ & $391 \pm 6,7$ \\
\hline Масса белка к массе желтка ${ }^{I}$ & $2,3 \pm 0,05$ & $2,5 \pm 0,03$ & $2,5 \pm 0,04$ & $2,5 \pm 0,04$ & $2,4 \pm 0,04$ \\
\hline \multicolumn{6}{|l|}{ Интенсивность окраски } \\
\hline \multirow[t]{2}{*}{ Единицы Хаук } & $94,3 \pm 0,93$ & $96,6 \pm 0,75$ & $95,1 \pm 0,58$ & $95,0 \pm 0,93$ & $94,1 \pm 0,85$ \\
\hline & \multicolumn{3}{|c|}{ В о з рас т 360 сут } & & \\
\hline \multicolumn{6}{|l|}{$\begin{array}{l}\text { Масса: } \\
\text { белка }\end{array}$} \\
\hline$\Gamma$ & $38,2 \pm 0,31$ & $37,3 \pm 0,22$ & $37,0 \pm 0,32$ & $37,5 \pm 0,27$ & $37,6 \pm 0,28$ \\
\hline$\%$ & 62,1 & 62,8 & 62,6 & 62,7 & 63,1 \\
\hline \multicolumn{6}{|l|}{ желтка } \\
\hline$\Gamma$ & $17,0 \pm 0,25$ & $16,0 \pm 0,15$ & $15,7 \pm 0,16$ & $15,6 \pm 0,16$ & $15,3 \pm 0,20$ \\
\hline$\%$ & 27,6 & 26,9 & 26,6 & 26,1 & 25,7 \\
\hline \multicolumn{6}{|l|}{ скорлупыC } \\
\hline$\Gamma$ & $6,3 \pm 0,09$ & $6,1 \pm 0,07$ & $6,4 \pm 0,11$ & $6,7 \pm 0,09$ & $6,7 \pm 0,09$ \\
\hline$\%$ & 10,3 & 10,3 & 10,8 & 11,2 & 11,2 \\
\hline
\end{tabular}


Индекс формы яйца, \%

Плотность яйца, г/см ${ }^{3 \mathrm{E}}$

Индекс белка, \%F

Индекс желтка, \%

Толщина скорлупы, мкм ${ }^{\mathrm{H}}$

Масса белка к массе желтка I

Интенсивность окраски

желтка, балл ${ }^{\mathrm{J}}$

Единицы Хаук

Macca:

$$
\begin{gathered}
\text { белка }^{\mathrm{A}} \\
\text { г } \\
\% \\
\text { желтка }^{\mathrm{B}} \\
\text { г } \\
\% \\
\text { скорлупы }^{\mathrm{C}} \\
\text { г } \\
\%
\end{gathered}
$$

Индекс формы яйца, \%

Плотность яйца, г/см ${ }^{3 \mathrm{E}}$

Индекс белка, \%F

Индекс желтка, \% $\mathrm{G}$

Толщина скорлупы, мкм ${ }^{\mathrm{H}}$

Масса белка к массе желтка

Интенсивность окраски

желтка, балл

Единицы Хаук

Macca:

$$
\begin{gathered}
\text { белка }^{\mathrm{A}} \\
\text { г } \\
\% \\
\text { желтка } \\
\text { В } \\
\% \\
\text { скорлупы } \\
\text { г } \\
\%
\end{gathered}
$$

Индекс формы яйца, \%

Плотность яйца, г/см ${ }^{3 \mathrm{E}}$

Индекс белка, \%F

Индекс желтка, \% $\mathrm{G}$

Толщина скорлупы, мкм ${ }^{\mathrm{H}}$

Масса белка к массе желтка

Интенсивность окраски

желтка, балл

Единицы Хаук

Macca:

$$
\begin{gathered}
\text { белка }^{\mathrm{A}} \\
\text { г } \\
\% \\
\text { желтка } \\
\text { В } \\
\% \\
\text { скорлупы } \\
\text { г } \\
\%
\end{gathered}
$$

Индекс формы яйца, \%

Плотность яйца, г/см ${ }^{3 \mathrm{E}}$

Индекс белка, \% $\mathrm{F}$

Индекс желтка, \% $\mathrm{G}$

Толщина скорлупы, мкм ${ }^{\mathrm{H}}$

Масса белка к массе желтка $\mathrm{I}$

Интенсивность окраски

желтка, балл ${ }^{\mathrm{J}}$

Единицы Хаук

$\begin{array}{ccc}78,5 \pm 0,24 & 78,7 \pm 0,25 & 78,5 \pm 0,25 \\ 1,086 \pm 0,001 & 1,089 \pm 0,001 & 1,095 \pm 0,001 \\ 11,3 \pm 0,28 & 10,6 \pm 0,37 & 11,5 \pm 0,45 \\ 47,0 \pm 0,52 & 46,4 \pm 0,46 & 46,7 \pm 0,36 \\ 372 \pm 4,4 & 372 \pm 3,4 & 386 \pm 7,4 \\ 2,3 \pm 0,06 & 2,3 \pm 0,03 & 2,4 \pm 0,04 \\ 3,3 \pm 0,10 & 3,4 \pm 0,10 & 3,6 \pm 0,15 \\ 92,1 \pm 0,90 & 90,3 \pm 1,13 & 92,5 \pm 1,21\end{array}$

В о 3 р а с т 420 сут

$$
\begin{gathered}
37,8 \pm 0,29 \\
62,0
\end{gathered}
$$

$17,0 \pm 0,18$

27,9

\section{$6,2 \pm 0,09$ \\ 10,1}

$77,4 \pm 0,24$

$1,089 \pm 0,001$

$11,4 \pm 0,37$

$46,6 \pm 0,55$

$370 \pm 5,5$

$2,2 \pm 0,03$

$3,3 \pm 0,10$

$92,8 \pm 1,10$$$
\begin{gathered}
36,4 \pm 0,27 \\
62,2
\end{gathered}
$$

$4 \pm 0,27$
62,2

$$
\begin{gathered}
16,0 \pm 0,19 \\
27,4
\end{gathered}
$$

$$
\begin{gathered}
6,1 \pm 0,09 \\
10,4
\end{gathered}
$$

$77,5 \pm 0,25$

$1,089 \pm 0,001$

$11,5 \pm 0,37$

$46,4 \pm 0,40$

$368 \pm 5,1$

$2,3 \pm 0,03$
$35,8 \pm 0,31$
62,0
$15,7 \pm 0,16$
27,1

$6,3 \pm 0,12$

10,9

$77,6 \pm 0,26$

$1,092 \pm 0,001$

$11,1 \pm 0,40$

$46,5 \pm 0,51$

$385 \pm 7,1$

$2,3 \pm 0,03$

$3,3 \pm 0,10$

$3,3 \pm 0,10$

$92,5 \pm 0,99 \quad 91,0 \pm 1,18$

В о 3 p а с т 450 сут

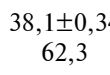

$16,9 \pm 0,18$
27,6

$6,2 \pm 0,09$

10,1

$76,7 \pm 0,26$

$1,089 \pm 0,001$

$10,1 \pm 0,32$

$46,7 \pm 0,39$

$364 \pm 4,4$

$2,3 \pm 0,04$

$3,3 \pm 0,09$

$88,7 \pm 1,05$

$$
\begin{gathered}
38,1 \pm 0,35 \\
62,9 \\
16,3 \pm 0,12 \\
26,9 \\
6,2 \pm 0,08 \\
10,2
\end{gathered}
$$

$76,2 \pm 0,25$

$1,090 \pm 0,001$

$9,7 \pm 0,32$

$45,9 \pm 0,34$

$376 \pm 4,3$

$2,3 \pm 0,03$

$3,4 \pm 0,10$

$87,4 \pm 1,12$

В с ред н м

$37,8 \pm 0,41$
62,6
$16,3 \pm 0,22$
27,0

$37,9 \pm 0,30$

$$
62,4
$$

$38,5 \pm 0,27$

62,9

$16,3 \pm 0,26$

26,9

$6,3 \pm 0,09$

10,4

$77,0 \pm 0,26$

$1,086 \pm 0,001$

$9,7 \pm 0,40$

$46,0 \pm 0,5$

$376 \pm 4,5$

$2,3 \pm 0,05$

$3,4 \pm 0,10$

$87,1 \pm 1,32$

$6,5 \pm 0,08$

10,7

$77,3 \pm 0,27$

$1,091 \pm 0,002$

$9,1 \pm 0,44$

$45,9 \pm 0,5$

$380 \pm 7,6$

$2,3 \pm 0,05$

$3,3 \pm 0,10$

$84,9 \pm 1,89$

$16,2 \pm 0,14$

26,5

$6,5 \pm 0,11$

10,6

$77,0 \pm 0,30$

$1,092 \pm 0,001$

$9,8 \pm 0,27$

$47,1 \pm 0,41$

$379 \pm 6,8$

$2,4 \pm 0,03$

$3,5 \pm 0,10$

$88,4 \pm 0,85$

$\begin{array}{ccccc}37,5 \pm 0,16 & 36,8 \pm 0,16 & 36,5 \pm 0,17 & 36,7 \pm 0,16 & 36,6 \pm 0,19 \\ 62,5 & 63,4 & 63,3 & 63,2 & 63,0 \\ 16,3 \pm 0,12 & 15,2 \pm 0,12 & 15,0 \pm 0,12 & 15,0 \pm 0,12 & 15,1 \pm 0,14 \\ 27,2 & 26,2 & 26,0 & 25,8 & 26,0 \\ & & & \\ 6,2 \pm 0,03 & 6,0 \pm 0,04 & 6,2 \pm 0,05 & 6,4 \pm 0,04 & 6,4 \pm 0,05 \\ 10,3 & 10,4 & 10,7 & 11,0 & 11,0 \\ 78,4 \pm 0,12 & 78,1 \pm 0,12 & 78,4 \pm 0,13 & 78,9 \pm 0,13 & 77,7 \pm 0,12 \\ 1,089 \pm 0,0004 & 1,089 \pm 0,0004 & 1,091 \pm 0,0006 & 1,094 \pm 0,0006 & 1,093 \pm 0,0006 \\ 11,6 \pm 0,17 & 11,7 \pm 0,19 & 11,9 \pm 0,22 & 11,5 \pm 0,23 & 11,7 \pm 0,18 \\ 46,9 \pm 0,21 & 46,9 \pm 0,21 & 47,0 \pm 0,22 & 47,0 \pm 0,23 & 46,9 \pm 0,21 \\ 371 \pm 2,0 & 369 \pm 2,1 & 382 \pm 2,8 & 390 \pm 2,7 & 389 \pm 2,7 \\ 2,3 \pm 0,02 & 2,4 \pm 0,02 & 2,5 \pm 0,02 & 2,5 \pm 0,02 & 2,5 \pm 0,02 \\ 3,2 \pm 0,05 & 3,2 \pm 0,06 & 3,3 \pm 0,06 & 3,2 \pm 0,06 & 3,1 \pm 0,05 \\ 92,3 \pm 0,45 & 92,5 \pm 0,51 & 92,4 \pm 0,60 & 91,4 \pm 0,63 & 91,7 \pm 0,71\end{array}$

$92,3 \pm 0,45$

$91,4 \pm 0,63$

$91,7 \pm 0,71$

П р и м е ч а н и е. А-К - показатели, а-е - группы.
$*, * *, * * *$ Различия между группами статистически значимы соответственно при $\mathrm{p}<0,05 ; \mathrm{p}<0,01$ и р $<0,001$.

Достоверные различия по показателям между группами:

для 210 сут $\mathrm{A}-* \mathrm{ab}, \mathrm{de} ; \mathrm{B}-* * * \mathrm{ab}, \mathrm{ac}, \mathrm{ad}, \mathrm{ae} ; \mathrm{D}-* \mathrm{bd}, * * \mathrm{ab}, \mathrm{ce}, * * * \mathrm{ae}, \mathrm{de} ; \mathrm{E}-* \mathrm{ad}, \mathrm{cd}, \mathrm{de}, * * \mathrm{bd}$,

***ae, be, ce; F - *ab, ac, **ad; G - *dc, **cd; H - **bd, be; I - *ab, ae, **ac, ***ad; K - *ac, ad; 
для 270 сут: $\mathrm{A}-* \mathrm{ad}, * * a \mathrm{a} ; \mathrm{B}-* \mathrm{be}$, ce, de, ***ab, ac, ad; C $-* \mathrm{bd}, * * a b, \mathrm{~cd} ; \mathrm{D}-* \mathrm{ae}, \mathrm{bd}, \mathrm{be}, \mathrm{ce}$, ***de; E - *bc, cd, ce, **ad, ae, ***bd, be; $\mathrm{G}-* \mathrm{bc} ; \mathrm{H}-* \mathrm{ad}, \mathrm{ae}, * * \mathrm{bd}, \mathrm{be} ; \mathrm{I}-* * \mathrm{ab}, \mathrm{ac}, \mathrm{ad} ; \mathrm{J}-* \mathrm{ab}, \mathrm{ce}, * * * \mathrm{ad}$, ae; $\mathrm{K}-*$ be;

для 360 сут: $\mathrm{A}-* \mathrm{ab}, \mathrm{ac}$; $\mathrm{B}-* * \mathrm{ab}, \mathrm{be}, * * * \mathrm{ac}, \mathrm{ad}, \mathrm{ae} ; \mathrm{C}-* \mathrm{bc}, \mathrm{cd}, \mathrm{ce}, * * \mathrm{ad}, \mathrm{ae}, * * * \mathrm{bd}, \mathrm{be} ; \mathrm{D}-* \mathrm{ad}$, ae, bd, cd, ce, **be, ***de; E - *ab, ***ac, ad, ae, bc, bd, be; F - *be, de; H $-* * * a d$, ae, bd, be; I $-*$ ae, $* * b e ;$ $\mathrm{K}-*$ de;

для 420 сут: $\mathrm{A}-* \mathrm{ae}, \mathrm{ce}, \mathrm{de}, * * \mathrm{ab}, * * * \mathrm{ac}, \mathrm{ad} ; \mathrm{B}-* \mathrm{bd}, * * * a b, \mathrm{ac}, \mathrm{ad}, \mathrm{ae} ; \mathrm{C}-* \mathrm{bd}, \mathrm{be} ; \mathrm{D}-* \mathrm{de}$; $\mathrm{E}-* \mathrm{ac}, \mathrm{bc}, \mathrm{ce}, * * \mathrm{ad}, \mathrm{bd}, \mathrm{de} ; \mathrm{H}-* \mathrm{be}, * * \mathrm{ad}, \mathrm{bd} ; \mathrm{I}-* \mathrm{be}, * * \mathrm{ad}, \mathrm{bd}$

для 450 сут: $\mathrm{C}-*$ ad, ae, bd, be; D — *bc, be, **bd; E - *ac, ae, cd, **bc, ***ce; G — *be; I — *be; $\mathrm{J}$ - различия между группами недостоверны; различия между группами по массе яйца недостоверны.

в среднем: А - **ab, ad, ae, ***ac; В - ***ab, ac, ad, ae; $\mathrm{C}-* * a e, b c, c d, c e, * * * a b, a d, b d, b e ;$ $\mathrm{D}-* \mathrm{be}, \mathrm{cd}, * * \mathrm{ad}, * * * \mathrm{ae}, \mathrm{bd}, \mathrm{ce}, \mathrm{de} ; \mathrm{E}-* \mathrm{ce}, * * \mathrm{ac}, \mathrm{bc}, \mathrm{cd}, * * * \mathrm{ad}, \mathrm{ae}, \mathrm{bd}, \mathrm{be} ; \mathrm{H}-* \mathrm{~cd}, * * \mathrm{ac}, * * * \mathrm{ad}, \mathrm{ae}, \mathrm{bc}, \mathrm{bd}$ be; I $-* * a b$, bc, bd, be, ***ac, ad, ae; J $-*$ ce.

От времени снесения яиц также зависело содержание белка и желтка в них. В яйцах, снесенных до $8^{00}$, абсолютная масса белка и желтка в среднем была наибольшей, в остальные периоды дня она достоверно ( $<<0,001$ $0,01)$ снижалась. Однако относительная масса белка в яйцах, собранных с $8^{00}$ до 1400 , в среднем увеличивалась с 62,5 до $63,4 \%$, а в конце дня (1400_ $16^{00}$ ) незначительно снижалась до 63,0 \%. У 420- и 450-суточных несушек относительная масса белка не изменяется в зависимости от времени яйцекладки. Относительная масса желтка в среднем снижалась к концу дня $\left(14^{00}-16^{00}\right)$ с 27,2 до 25,8 \%. Изменение массы белка и желтка в зависимости от времени яйцекладки влечет за собой достоверное $(\mathrm{p}<0,01-0,001)$ увеличение соотношения массы белка и желтка (в среднем с 2,3 до 2,5). Таким образом, в яйцах, снесенных рано утром, больше желтка и меньше белка, чем в остальные периоды дня. Следовательно, питательная ценность и выход сухих веществ яиц, снесенных в период с $5^{00}$ до $8^{00}$, выше, чем снесенных в остальное время дня, что служит положительным фактором для глубокой переработки яиц.

Увеличение абсолютной массы белка, желтка и, следовательно, массы яиц, снесенных до $8^{00}$, по нашему мнению, можно объяснить тем, что первые яйца в цикле после паузы в яйцекладке (от одних до нескольких суток) куры сносят именно рано утром.

В среднем за период опыта время яйцекладки не повлияло на такие показатели качества яиц как индекс белка и единицы Хау, но у молодой птицы (210-суточной) белок в яйцах, снесенных до $8^{00}$, более жидкий, чем в других партиях. В этой группе индекс белка был достоверно ниже (p $<0,01$ 0,05), чем в яйцах 2-й, 3-й и 4-й групп соответственно на 0,9; 1,0 и 1,3\%, а единицы Хау - соответственно на 1,$8 ; 2,1$ и 2,1 ед., что важно при инкубации яиц, так как плотный белок влияет на эмбриональное развитие птицы и результаты инкубации ухудшаются на 1-5 \% (38). Однако с точки зрения потребительских качеств у яиц с высокой плотностью белка лучше аминокислотный состав и вкус, а также пенообразующая способность (39).

Независимо от возраста несушек (за исключением 210- и 450-суточного) максимальное значение индекса формы имели яйца, снесенные с $12^{00}$ до 1400 . В среднем за период наблюдения в указанной группе этот показатель был достоверно выше ( $<<0,05-0,001)$, чем в остальных группах. Во все возрастные периоды и в среднем за время эксперимента наименьший индекс формы отмечали у яиц, снесенных с $14^{00}$ до $16^{00}$.

По данным химического анализа (табл. 3), в среднем за период опыта не было выявлено существенных различий между группами яиц по содержанию влаги, кальция в скорлупе, каротиноидов, витаминов А и Е в желтке и витамина В2 в белке. Однако по содержанию витамина В2 в желтке яйца, снесенные с $5^{00}$ до $8^{00}$ во все возрастные периоды (за исключением 450 сут, когда незначительное превосходство было в пользу яиц, снесенных с $8^{00}$ до $\left.10^{00}\right)$ и в среднем за период опыта достоверно (p $\left.<0,05-0,001\right)$ пре- 
восходили яйца, снесенные в другие периоды дня. Е. Tůmova c coaвт. (22) сообщают о значительном влиянии времени снесения яйца на содержание в скорлупе кальция: в яйцах, снесенных в 730 , его содержание составляло $35,2 \%$, а снесенных в $15^{30}$ - всего $34,2 \%$. В нашем исследовании такая закономерность не подтвердилась.

Выполненные нами наблюдения выявили тенденцию к недостоверному увеличению содержания общего холестерина в желтке яиц, отложенных с $5^{00}$ до $8^{00}$, в среднем за период наблюдений. Е. Tůmova с соавт. (17) также фиксировали недостоверно более высокое содержание холестерина в желтке ранних утренних яиц по сравнению с дневными. В то же время это противоречит результатам A.M. Abdalla с соавт. (29), которые, наоборот, отмечали значительно меньшее количество общего холестерина в утренних яйцах, чем в дневных, в расчете как на единицу массы желтка (12,53 против 16,23 мг/г), так и на одно яйцо (176,63 против 221,14 мг/яйцо).

3. Результаты химического анализа яиц разного времени снесения у кур промышленного стада кросса Haisex Brown (по $n=15$ в 3 объединенных пробах для каждого периода, $M \pm \mathrm{SEM}$; виварий Селекционно-генетического центра «Загорское экспериментальное племенное хозяйство» ВНИТИП, 2020 год)

\begin{tabular}{|c|c|c|c|c|c|}
\hline \multirow[b]{2}{*}{ Показатель } & \multicolumn{5}{|c|}{ Время сбора } \\
\hline & $\begin{array}{c}5^{00}-8^{00} \\
(1-я \text { группа })^{a}\end{array}$ & $\begin{array}{c}8^{00}-10^{00} \\
(2-я \text { группа })^{b}\end{array}$ & $\begin{array}{c}10^{00}-12^{00} \\
(3-я \text { группа })^{c}\end{array}$ & $\begin{array}{c}12^{00}-14^{00} \\
(4-я \text { группа })^{d}\end{array}$ & $\begin{array}{c}14^{00}-16^{00} \\
(5-я \text { группа })^{\mathrm{e}}\end{array}$ \\
\hline \multicolumn{6}{|c|}{ В о з раст 210 сут } \\
\hline \multicolumn{6}{|l|}{ Содержание: } \\
\hline влаги, \% & 75,76 & 75,43 & 75,75 & 76,18 & 76,09 \\
\hline $\begin{array}{l}\text { кальция в скорлупе, \%А } \\
\text { в желтке, мкг/г: }\end{array}$ & $36,91 \pm 0,30$ & $36,91 \pm 0,33$ & $37,66 \pm 0,10$ & $37,27 \pm 0,18$ & $36,34 \pm 0,07$ \\
\hline каротиноидов В & $6,29 \pm 0,03$ & $6,52 \pm 0,10$ & $6,28 \pm 0,02$ & $6,08 \pm 0,09$ & $6,28 \pm 0,01$ \\
\hline витамина $\mathrm{A}^{\mathrm{C}}$ & $4,68 \pm 0,14$ & $4,78 \pm 0,09$ & $4,78 \pm 0,30$ & $4,75 \pm 0,11$ & $4,68 \pm 0,03$ \\
\hline витамина $\mathrm{E}^{\mathrm{D}}$ & $52,91 \pm 2,21$ & $52,82 \pm 1,91$ & $54,65 \pm 1,98$ & $53,62 \pm 3,01$ & $53,79 \pm 1,68$ \\
\hline витамина $\mathrm{B}_{2} \mathrm{E}$ & $5,33 \pm 0,07$ & $4,43 \pm 0,16$ & $3,63 \pm 0,15$ & $4,20 \pm 0,15$ & $3,98 \pm 0,01$ \\
\hline холестерина, ммоль/лF & $42,1 \pm 0,10$ & $43,1 \pm 1,25$ & $40,1 \pm 1,24$ & $38,7 \pm 0,94$ & $42,8 \pm 1,12$ \\
\hline в белке витамина В2, мкг/ГG & $3,33 \pm 0,08$ & $3,76 \pm 0,01$ & $3,37 \pm 0,20$ & $3,61 \pm 0,17$ & $3,73 \pm 0,08$ \\
\hline \multicolumn{6}{|c|}{ В о з р аст 270 сут } \\
\hline Содержание: & & & & & \\
\hline влаги & 75,90 & 75,48 & 75,98 & 75,37 & 74,79 \\
\hline $\begin{array}{l}\text { кальция в скорлупе, \%А } \\
\text { в желтке, мкг/г: }\end{array}$ & $35,92 \pm 0,35$ & $36,75 \pm 0,20$ & $36,51 \pm 0,13$ & $36,47 \pm 0,23$ & $36,15 \pm 0,46$ \\
\hline каротиноидов ${ }^{B}$ & $2,60 \pm 0,03$ & $2,54 \pm 0,07$ & $2,54 \pm 0,07$ & $2,45 \pm 0,06$ & $2,86 \pm 0,03$ \\
\hline витамина $\mathrm{A}^{\mathrm{C}}$ & $5,45 \pm 0,14$ & $5,39 \pm 0,08$ & $5,17 \pm 0,05$ & $4,88 \pm 0,15$ & $5,36 \pm 0,12$ \\
\hline витамина ED & $110,26 \pm 2,25$ & $107,47 \pm 2,65$ & $108,98 \pm 2,10$ & $105,32 \pm 1,01$ & $105,29 \pm 1,21$ \\
\hline витамина $\mathrm{B}_{2} \mathrm{E}$ & $5,58 \pm 0,26$ & $5,49 \pm 0,02$ & $4,50 \pm 0,18$ & $4,72 \pm 0,06$ & $5,16 \pm 0,03$ \\
\hline холестерина, ммоль/л $F$ & $82,9 \pm 2,42$ & $74,4 \pm 3,10$ & $78,1 \pm 1,76$ & $75,2 \pm 2,71$ & $74,7 \pm 2,14$ \\
\hline в белке витамина В2, мкг $/ \Gamma^{G}$ & $3,64 \pm 0,16$ & $4,11 \pm 0,11$ & $4,07 \pm 0,05$ & $4,16 \pm 0,17$ & $3,87 \pm 0,19$ \\
\hline \multicolumn{6}{|c|}{ В о з р а с т 360 сут } \\
\hline Содержание: & & & & & \\
\hline влаги & 75,76 & 75,43 & 75,75 & 76,18 & 76,09 \\
\hline кальция в скорлупе, \%А & $36,77 \pm 0,36$ & $37,14 \pm 0,23$ & $37,14 \pm 0,21$ & $36,59 \pm 0,42$ & $36,96 \pm 0,13$ \\
\hline \multicolumn{6}{|l|}{ в желтке, мкг/г: } \\
\hline каротиноидов ${ }^{B}$ & $9,43 \pm 0,71$ & $9,37 \pm 0,09$ & $10,2 \pm 0,27$ & $9,63 \pm 0,09$ & $10,09 \pm 0,32$ \\
\hline витамина $\mathrm{A}^{\mathrm{C}}$ & $5,16 \pm 0,04$ & $5,20 \pm 0,13$ & $5,44 \pm 0,12$ & $5,70 \pm 0,35$ & $5,16 \pm 0,21$ \\
\hline витамина $\mathrm{E}^{\mathrm{D}}$ & $49,23 \pm 2,39$ & $47,27 \pm 2,86$ & $48,53 \pm 0,93$ & $51,78 \pm 0,76$ & $55,74 \pm 1,55$ \\
\hline витамина В 2 E & $5,04 \pm 0,32$ & $4,91 \pm 0,08$ & $4,58 \pm 0,19$ & $4,51 \pm 0,28$ & $4,19 \pm 0,18$ \\
\hline холестерина, ммоль/лF & $63,7 \pm 4,72$ & $69,7 \pm 7,56$ & $52,8 \pm 4,85$ & $56,6 \pm 5,47$ & $51,3 \pm 4,77$ \\
\hline в белке витамина В2, мкг/ГG & $3,42 \pm 0,24$ & $3,18 \pm 0,16$ & $3,30 \pm 0,41$ & $3,32 \pm 0,30$ & $3,18 \pm 0,24$ \\
\hline \multicolumn{6}{|c|}{ В о з р а с т 420 сут } \\
\hline Содержание: & & & & & \\
\hline влаги & 74,52 & 76,07 & 75,53 & 75,43 & 74,35 \\
\hline кальция в скорлупе, \%А & $35,82 \pm 0,16$ & $36,67 \pm 0,19$ & $36,48 \pm 0,18$ & $36,20 \pm 0,26$ & $36,60 \pm 0,44$ \\
\hline \multicolumn{6}{|l|}{ в желтке, мкг/г: } \\
\hline каротиноидов ${ }^{B}$ & $4,44 \pm 0,15$ & $4,66 \pm 0,23$ & $4,34 \pm 0,20$ & $4,50 \pm 0,06$ & $4,31 \pm 0,06$ \\
\hline витамина А & $5,38 \pm 0,35$ & $5,75 \pm 0,08$ & $5,70 \pm 0,20$ & $5,42 \pm 0,31$ & $5,46 \pm 0,12$ \\
\hline витамина E & $68,97 \pm 3,32$ & $71,81 \pm 0,71$ & $76,15 \pm 1,53$ & $73,23 \pm 3,23$ & $71,43 \pm 8,55$ \\
\hline витамина $\mathrm{B}_{2} \mathrm{C}$ & $5,67 \pm 0,12$ & $4,70 \pm 0,19$ & $5,55 \pm 0,12$ & $4,57 \pm 0,24$ & $4,77 \pm 0,07$ \\
\hline холестерина, ммоль/л $\mathrm{D}$ & $83,3 \pm 8,38$ & $76,9 \pm 9,98$ & $61,9 \pm 4,52$ & $67,1 \pm 4,49$ & $68,2 \pm 5,54$ \\
\hline в белке витамина В2, мкг/ГЕ & $3,91 \pm 0,28$ & $4,38 \pm 0,18$ & $4,51 \pm 0,15$ & $4,19 \pm 0,22$ & $4,32 \pm 0,13$ \\
\hline
\end{tabular}


Содержание:

влаги

кальция в скорлупе, \%А

в желтке, мкг/г:

каротиноидов $\mathrm{B}$

витамина $\mathrm{A}^{\mathrm{C}}$

витамина $\mathrm{E}^{\mathrm{D}}$

витамина В2

холестерина, ммоль/л $\mathrm{F}$

в белке витамина B2, мкг/Г $\mathrm{G}$

Содержание:

влаги

кальция в скорлупе, \%А

в желтке, мкг/г:

каротиноидов ${ }^{\mathrm{B}}$

витамина $\mathrm{A}^{\mathrm{C}}$

витамина $\mathrm{E}^{\mathrm{D}}$

витамина В2

холестерина, ммоль/л ${ }^{\mathrm{F}}$

в белке витамина В2, мкг/ $\mathrm{r}^{\mathrm{G}}$

В о з рас т 450 сут

74,83
$37,26 \pm 0,05$
$3,47 \pm 0,33$
$4,64 \pm 0,06$
$64,23 \pm 1,74$
$5,07 \pm 0,21$
$30,7 \pm 0,61$
$4,15 \pm 0,41$

75,65
$37,04 \pm 0,20$

75,25
$36,44 \pm 0,3$

$3,11 \pm 0,32$

$5,20 \pm 0,20$

$69,39 \pm 3,64$

$5,13 \pm 0,09$

$31,9 \pm 1,00$

$4,19 \pm 0,44$

В средн е

75,35
$36,54 \pm 0,18$

$5,24 \pm 0,66$
$5,06 \pm 0,11$
$69,12 \pm 5,90$
$5,34 \pm 0,11$
$60,54 \pm 3,20$
$3,69 \pm 0,13$

\section{5,61}

$36,90 \pm 0,10$

$5,24 \pm 0,67$

$5,26 \pm 0,10$

$69,19 \pm 5,42$

$4,93 \pm 0,11$

$59,20 \pm 3,30$

$3,92 \pm 0,14$

$3,69 \pm 0,13$

П р и м е ч а н и е. А-Е - показатели, а-е - группы.

*, **, *** Различия между группами статистически значимы соответственно при $\mathrm{p}<0,05 ; \mathrm{p}<0,01$ и $\mathrm{p}<0,001$. Достоверные различия по показателям между группами: для 210 сут: $\mathrm{A}-* \mathrm{ab}, \mathrm{ac}, * * \mathrm{~cd}, \mathrm{ce} ; \mathrm{B}-* \mathrm{ab}, \mathrm{ad}, \mathrm{bc}, \mathrm{be}, \mathrm{cd}, \mathrm{de}, * * \mathrm{bd} ; \mathrm{E}-* \mathrm{be}, \mathrm{cd}, \mathrm{ce}, * * \mathrm{bc}, * * * a b, \mathrm{ac}$, ad, ae; F - *bd, de, **ad; $\mathrm{G}-* * * a b$, be; для 270 сут: $\mathrm{B}-* * * a e$, be, ce, de; $\mathrm{C}-* \mathrm{ad}, \mathrm{bc}, \mathrm{de}, * * \mathrm{bd} ; \mathrm{E}-* * \mathrm{ac}, \mathrm{ad}, * * * \mathrm{bc}, \mathrm{bd}, \mathrm{be}, \mathrm{de} ; \mathrm{F}-* a b$, ae; $\mathrm{G}-* \mathrm{ab}, \mathrm{ac}, \mathrm{ad}$; для 360 сут: $\mathrm{B}-* \mathrm{bc}$, ce; $\mathrm{C}-* \mathrm{ac} ; \mathrm{D}-*$ ae, be, de, cd, **ce; $\mathrm{E}-* \mathrm{ae}, * * \mathrm{be}, * * * \mathrm{de}$; для 420 сут: $\mathrm{A}-* \mathrm{ac}, * * a b ; \mathrm{B}-* \mathrm{de} ; \mathrm{D}-* \mathrm{bc}$; $\mathrm{E}-* \mathrm{~cd}, * * \mathrm{bc}, * * * a b, \mathrm{ad}$, ae, ce; $\mathrm{F}-* \mathrm{ac}$; для 450 сут: $\mathrm{A}-* \mathrm{ac}, \mathrm{cd}, \mathrm{de}, * * \mathrm{be}, * * * \mathrm{ab}, \mathrm{ae} ; \mathrm{C}-* \mathrm{ab}, \mathrm{ad}, * * \mathrm{ae}, * * * a c ; \mathrm{D}-* * * \mathrm{ac}, \mathrm{ad}, \mathrm{ae} ; \mathrm{E}-* \mathrm{de}$, $* * \mathrm{ad}, * * * \mathrm{bd} ; \mathrm{F}-* \mathrm{ad}, \mathrm{cd}$; в среднем: $\mathrm{E}-*$ ab, be, **ac, bd, ***ad, ae.

Итак, у несушек кросса Haisex Brown при постоянном режиме освещения (включение света в $5^{00}$, выключение в $19^{00}$ ) и клеточном содержании время яйцекладки значительно влияет на морфологические показатели качества яиц. У яиц, снесенных до $8^{00}$, в среднем за период наблюдений на 2,1-2,5 г, или на 3,6-4,4 \%, выше средняя масса, на 7,2-8,7 \% - абсолютная и на 1,0-1,4 \% - относительная масса желтка и, следовательно, ниже на 4,2-8,0 \% соотношение массы белка и желтка. У яиц, снесенных с $12^{00}$ до $16^{00}$, лучше качество скорлупы, о чем свидетельствуют более высокие показатели массы скорлупы (на 3,2-6,7 \%), ее бо́льшая толщина (на 1,8-5,7 \%) и более высокая плотность яиц (на 0,18-0,46 \%). Индекс формы яиц изменялся криволинейно, его максимальным значением $(78,9 \%)$ характеризовались яйца, снесенные с $12^{00}$ до 1400 , минимальным $(77,7 \%)$ - снесенные в конце дня (с $14^{00}$ до $\left.16^{00}\right)$. Снесенные до полудня яйца имели большее количество дефектов скорлупы (бой и насечка), а в вечерних партиях отсутствовали яйца высшей категории. В пределах каждого возраста показатели между группами в основном различались мало. Однако масса яйца в каждой группе с возрастом в целом повышалась (так, в группе яиц сбора

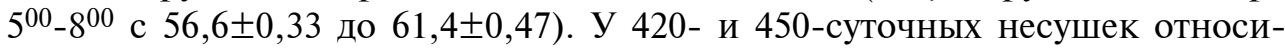
тельная масса белка не изменяется в зависимости от времени яйцекладки. У молодой (210-суточной) птицы белок яиц, снесенных до $8^{00}$, более жидкий. Независимо от возраста (за исключением 210- и 450-суточного) максимальное значение индекса формы имели яйца, снесенные с $12^{00}$ до $14^{00}$. Во все возрастные периоды и в среднем за время эксперимента наименьший индекс формы отмечали у яиц, снесенных с 1400 до $16^{00}$. Время яйцекладки не повлияло на химический состав яиц, за исключением содержания витамина В2 в желтке: яйца, собранные с $5^{00}$ до $8^{00}$, достоверно превосхо- 
дили по этому показателю яйца, собранные в более поздние сроки (кроме 450-суточных несушек, у которых незначительное превосходство было в пользу яиц, снесенных с $8^{00}$ до $10^{00}$ ). Повышенное содержание холестерина в желтке отмечали в яйцах птицы 270- и 420-суточного возраста (в целом с возрастом птицы оно повышалось), каротиноидов - у 360-суточных несушек. Содержание витамина А в желтке также имело тенденцию к повышению в зависимости от возраста кур. Полученные экспериментальные данные позволят оптимизировать график сбора яиц, подбор и использование упаковочной тары для снижения повреждения товарной продукции. В cелекционных программах ранняя яйцекладка может служить признаком, обеспечивающим лучшее качество пищевых и инкубационных яиц. В дальнейших экспериментах мы планируем изучить влияние времени снесения яиц на рост, развитие и однородность эмбрионов, результаты инкубации и последующую продуктивность птицы.

ФГБНУ ФНЦ Всероссийский научно-исследовательский и технологический институт птицеводства РАН,

Поступила в редакцию

141311 Россия, Московская обл., г. Сергиев Посад, ул. Птицеградская, 10, 10 марта 2021 года

e-mail: alexk@vnitip.ru凶

Sel'skokhozyaistvennaya biologiya [Agricultural Biology], 2021, V. 56, № 4, pp. 795-808

\section{QUALITY PARAMETERS IN EGGS OF LAYER CROSS Hisex Brown AS AFFECTED BY THE OVIPOSITION TIME}

\section{A.Sh. Kavtarashvili}

Federal Scientific Center All-Russian Research and Technological Poultry Institute RAS, 10, ul. Ptitsegradskaya, Sergiev Posad, Moscow Province, 141311 Russia, e-mail alexk@vnitip.ru ( $\square$ corresponding author)

ORCID:

Kavtarashvili A.Sh. orcid.org/0000-0001-9108-1632

The author declares no conflict of interests

Received March 10, 2021

doi: 10.15389 /agrobiology.2021.4.795eng

\section{Abstract}

Chicken eggs are valuable and chip source of the nutrients in human diets; this fact has propelled the interest toward the availability of this commodity and modification of its chemical composition in desirable directions. The morphology of the eggs is closely correlated with certain parameters of nutritive value and shelf life. The formation of eggs is a long process: the maturation of large yellow follicles in the ovarian hierarchy (until the ovulation) lasts for 7-10 days; the formation of egg in the oviduct (since ovulation to oviposition) takes 22.5-26.1 hours, depending on age and productivity level in parental hen. The quality of eggs is affected by multiple factors acting before the oviposition (breed and cross of chicken, individual physiological peculiarities, live bodyweight, laying rate, oviposition time, age, the regimes of management and nutrition, artificially induced moult, stresses, health status) and after the oviposition (conditions of collection, transportation, storage, washing and sanitary treatments, the effects of these factors being also depend on the initial egg quality formed before the oviposition. The optimization of egg quality requires the thorough knowledge on mechanisms and factors involved. In the study presented it was found out that oviposition can affect different parameters of egg quality though insignificantly with the exception of B2 content. The effects of the oviposition time on egg quality was studied on five treatments of commercial Hisex Brown layers (Hendrix Genetics BV, the Netherlands) since 210 to 450 days of age housed in cage batteries mounted in standard windowless poultry house ( 7 birds per cage) with constant lighting regime 14L: 10D with the onset of lighting at $5 \mathrm{am}$, setout at $7 \mathrm{pm}$. The eggs were collected during 5 periods of a day: 5-8 am (treatments 1), 8-10 am (treatment 2), 10-12 am (treatment 3). 0-2 pm Treatment 4), and 2-4 pm. Average weight of the "earliest" eggs (laid until 8 am) was significantly higher (by 2.1-2.5 g or 3.6-4.4\%, p $<0.001$ ) as compared to later periods; absolute yolk weight was higher by $7.2-8.7 \%$, relative yolk weight by $1.0-1.4 \%(\mathrm{p}<0.001)$; the resulting albumen/yolk ratio was lower by $4.2-8.0 \%(\mathrm{p}<0.01-0.001)$. The late eggs (laid between 0 and $4 \mathrm{pm}$ ) featured better eggshell quality as indicated by increased average eggshell weight (by 3.2-6.7 \%), eggshell thickness (by 1.8-5.7\%), and egg density (by 0.18-0.46 \%). The shape index varied from $78.9 \%(0-2 \mathrm{pm})$ to $77.7 \%(2-4 \mathrm{pm})$. Chemical composition of the eggs 
was not significantly affected by oviposition time with the exception of the significantly higher concentrations of vitamin $\mathrm{B}_{2}$ in yolk at early hours $(5-8 \mathrm{am})$ as compared to later hours $(\mathrm{p}<0.05-0.001)$. Earlier eggs (5-12 am) featured higher percentages of cracks and crackles while "evening" eggs featured the absence of extra-heavy eggs ( $>75 \mathrm{~g})$; other external parameters of egg quality were generally similar in all treatments; however, egg weight tended to increase with hen age. The relative weight of the albumen was similar at 420 and 450 days of age, with the minimal index shape eggs laid in the interval $0-2 \mathrm{pm}$ being found (with the exception of 210 and 450 days of age; $\mathrm{p}<0.05-0.001$ ). The increases in the concentration of total cholesterol in yolk was found at 270 and 420 days of hens' age (with general trend to increase with age). The age-related increase in the concentration of carotenoids in yolk was found at 360 days of age. As well as the trend to higher concentration of vitamin A in yolk.

Keywords: Gallus gallus L., laying hens, laying time, egg weight, yolk weight, shell weight, shell thickness, egg shape index, quality defects, chemical composition, vitamin $\mathrm{B}_{2}$.

\section{R E F E R E N C ES}

1. Kavtarashvili A.Sh., Fisinin V.I., Buyarov V.S., Kolokol'nikova T.N. The effects of lighting regimes on the oviposition time and egg quality in laying hens (review). Sel'skokhozyaistvennaya biologiya [Agricultural Biology], 2019, 54(6): 1095-1109 (doi: 10.15389/agrobiology.2019.6.1095eng).

2. Tůmová E., Ledvinka Z. The effect of time of oviposition and age on egg weight, egg components weight and eggshell quality. Archiv für Geflügelkunde, 2009, 73(2): 110-115.

3. Tsarenko P.P. Povyshenie kachestva produktsii ptitsevodstva: pishchevye i inkubatsionnye yaitsa [Improving the quality of poultry products: food and hatching eggs]. Leningrad, 1988 (in Russ.).

4. Ali A., Ramazan Y. The relationships among egg quality characteristic of different hybrid layers to forced molting programs with and without feed withdrawal. Journal of Animal and Veterinary Advances, 2010, 9(4): 710-715 (doi: 10.3923/javaa.2010.710.715).

5. Rayan G.N., Galal A., Fathi M.M., El-Attar A.H. Impact of layer breeder flock age and strain on mechanical and ultrastructural properties of eggshell in chicken. International Journal of Poultry Science, 2010, 9(2): 139-147 (doi: 10.3923/ijps.2010.139.147).

6. Van Den Brand H., Parmentier H.K., Kemp B. Effects of housing system (outdoor vs. cages) and age of laying hens on egg characteristics. Poultry Science, 2004, 45(6): 745-752 (doi: 10.1080/00071660400014283).

7. Jin Y.H., Lee K.T., Lee W.I., Han Y.K. Effects of storage temperature and time on the quality of eggs from laying hens at peak production. Asian-Australasian Journal of Animal Sciences, 2011, 24(2): 279-284 (doi: 10.5713/ajas.2011.10210).

8. Brake J. Relationship of egg weight, specific gravity, and shell weight to time of oviposition and feeding in broiler breeders. Poultry Science, 1985, 64(11): 2037-2040 (doi: 10.3382/ps.0642037).

9. Lee K.D., Choi J.H. Interrelationships among time of oviposition, egg weight, shell weight, and rate of production of laying hens. Poultry Science, 1985, 64(12): 2256-2258 (doi: 10.3382/ps.0642256).

10. Hashiguchi M. Relationship of position of egg in sequence to eggshell quality in laying hen. Japanese Poultry Science, 1996, 33: 230-234 (doi: 10.2141/jpsa.33.230).

11. Pavlovski Z., Vitorović D., Škrbić Z., Vračar S. Influence of limestone particle size in diets for hens and oviposition time on eggshell quality. Acta Veterinaria, Belgrade, 2000, 50(1): 37-42 (doi: 123456789/3).

12. Tůmová E., Zita L., Hubený M., Skřivan M., Ledvinka Z. The effect of oviposition time and genotype on egg quality characteristics in egg type hens. Czech Journal of Animal Science, 2007, 52(1): 26-30 (doi: 10.17221/2326-CJAS).

13. Yannakopoulos A.L., Tserveni-Gousi A.S., Nikokyris P.N. Egg composition as influenced by time of oviposition, egg weight, and age of hens. Archiv für Geflügelkunde, 1994, 58(5): 206-213.

14. Harms R.H. Specific gravity of eggs and eggshell weight from commercial layers and broiler breeders in relation to time of oviposition. Poultry Science, 1991, 70(5): 1099-1104 (doi: 10.3382/ps.0701099).

15. Patterson P.H. The relationship of oviposition time and egg characteristics to the daily light: dark cycle. Journal of Applied Poultry Research, 1997, 6(4): 381-390 (doi: 10.1093/japr/6.4.381).

16. Aksoy T., Yilmaz M., Tuna Y.T. The effect of oviposition time on egg quality and the possibility of estimating egg shell weight using a formula in commercial layers. Turkish Journal of Veterinary and Animal Sciences, 2001, 25: 811-816.

17. Tůmová E., Ledvinka Z., Skřivan M., Englmaierová M., Zita L. Effect of time of oviposition on egg quality in egg and meat type hens. Scientia Agriculturae Bohemica, 2008, 39(3): 269-272.

18. Tůmová E., Ebeid T. Effect of time of oviposition on egg quality characteristics in cage and in a litter housing system. Czech Journal of Animal Science, 2005, 50(3): 129-134 (doi: 10.17221/4006CJAS).

19. Tůmová E., Skřivan M., Englmaierová M., Zita L. The effect of genotype, housing system and egg collection time on egg quality in egg type hens. Czech Journal of Animal Science, 2009, 54(1): 
17-23 (doi: 10.17221/1736-CJAS).

20. Hrnčár C., Hässlerová M., Bujko J. The effect of oviposition time on egg quality parameters in Brown Leghorn, Oravka and Brahma hens. Scientific Papers: Animal Science and Biotechnologies, 2013, 46(1): 53-57.

21. Kryeziu A.J., Mestani N., Kamberi M., Berisha H. Effect of hen age and oviposition time on egg quality parameters. Proc. XIV European Symposium on the Quality of Eggs and Egg Products and XX European Symposium on the Quality of Poultry Meat. Leipzig, Germany, 2011: b-047 (doi: 10.13140/RG.2.1.1675.2808).

22. Tůvá E., Gous R.M., Tyler N. Effect of hen age, environmental temperature, and oviposition time on egg shell quality and eggshell and serum mineral contents in laying and broiler breeder hens. Czech Journal of Animal Science, 2014, 59(9): 435-443 (doi: 10.17221/7655-CJAS).

23. Kebreab E., France J., Kwakkel R.P., Lesson S., Darmani Kuhi H., Dijkstra J. Development and evaluation of a dynamic model of calcium and phosphorus flows in layers. Poultry Science, 2009, 88(3): 680-689 (doi: 10.3382/ps.2008-00157).

24. Samiullah S., Roberts J., Chousalkar K. Oviposition time, flock age, and egg position in clutch in relation to brown eggshell color in laying hens. Poultry Science, 2016, 95(9): 2052-2057 (doi: 10.3382/ps/pew197).

25. Campo J.L., Escudero J. Relationship between egg-shell colour and two measurements of shell strength in the Vasca breed. British Poultry Science, 1984, 25(4): 467-476 (doi: 10.1080/00071668408454888).

26. Curtis P.A., Gardner F.A., Mellor D.B. A comparison of selected quality and compositional characteristics of brown and white shell eggs. II. Interior quality. Poultry Science, 1985, 64(2): 302-306 (doi: 10.3382/ps.0640302).

27. Jones D.R., Musgrove M.T., Anderson K.E., Thesmar H.S. Physical quality and composition of retail shell eggs. Poultry Science, 2010, 89(3): 582-587 (doi: 10.3382/ps.2009-00315).

28. Mertens K., Vaesen I., Loffel J., Kemps B., Kamers B., Perianu C., Zoons J., Darius P., Decuypere E., De Baerdemaeker J., De Ketelaere B. The transmission color value: A novel egg quality measure for recording shell color used for monitoring the stress and health status of a brown layer flock. Poultry Science, 2010, 89(3): 609-617 (doi: 10.3382/ps.2009-00261).

29. Abdalla M.A., Ochi E.B. Effect of laying hen's age and oviposition time on egg cholesterol contents. Science Letters, 2018, 6(1): 42-46.

30. Adaptivnaya resursosberegayushchaya tekhnologiya proizvodstva yaits: monografiya /Pod redaktsiei V.I. Fisinina, A.Sh. Kavtarashvili [Adaptive resource-saving egg production technology: monograph. V.I. Fisinin, A.Sh. Kavtarashvili]. Sergiev Posad, 2016 (in Russ.).

31. Kulikov L.V. Praktikum po ptitsevodstvu [Poultry farming: practical works]. Moscow, 2002 (in Russ.).

32. Dyadichkina L.F., Podnyakova N.S., Melekhina T.A., Tsilinskaya T.A., Gura I.V., SHevyakov A.N., KHrebtova E.V., Rebrakova T.M., Silaeva A.V. Biologicheskii kontrol' pri inkubirovanii yaits sel'skokhozyaistvennoi ptitsy: metodicheskie nastavleniya [Biological control during incubation of poultry eggs: methodological guidelines]. Sergiev Posad, 2014 (in Russ.).

33. Mokshina N.Ya., Khokhlov V.Yu., Shlyakhina Yu.V., Selemenov V.F. Vestnik VGU. Seriya: KHimiya, Biologiya, Farmatsiya, 2003, 2: 53-55 (in Russ.).

34. Charvátová V., Tůmová E. Time of oviposition and egg composition: a review. Scientia Agriculturae Bohemica, 2010, 41(3): 190-195.

35. Zakaria A.H., Plumstead P.W., Romerosanchez H., Leksrisompong N., Osborne J., Brake J. Oviposition pattern, egg weight, fertility, and hatchability of young and old broiler breeders. Poultry Science, 2005, 84(9): 1505-1509 (doi: 10.1093/ps/84.9.1505).

36. Zakaria A.H., Plumstead P.W., Romero-Sanchez H., Leksrisompong N., Brake J. The effects of oviposition time on egg weight loss during storage and incubation, fertility, and hatchability of broiler hatching eggs. Poultry Science, 2009, 88(12): 2712-2717 (doi: 10.3382/ps.2009-00069).

37. Ketta M., Tůmová E. Eggshell structure, measurements, and quality-affecting factors in laying hens. Czech Journal of Animal Science, 2016, 61(7): 299-309 (doi: 10.17221/46/2015-CJAS).

38. Stanishevskaya O. Zhivotnovodstvo Rossii, 2008, 6: 17-18 (in Russ.).

39. Spiridonov I.P., Mal'tsev A.B., Dymkov A.B. Inkubatsiya yaits sel'skokhozyaistvennoi ptitsy ot A do $Y a$ [Incubation of poultry eggs from A to Z]. Omsk, 2017 (in Russ.). 